\title{
ESPACIO MiniTEA: DESCUBRIR, EXPERIMENTAR Y CREAR
}

MiniTEA space: Discover, experiment an create Paloma Tudela Caño

ISSN (imp): 1390-4825

ISSN (e): 2477-9199

Fecha de recepción: 04/12/18

Fecha de aceptación: 10/12/18 


\section{Resumen:}

El Espacio MiniTEA es un lugar dentro del museo Tenerife Espacio de la Artes, cuya razón de ser es facilitar la comunicación entre el público -principalmente infantil y familiar- y los contenidos del mismo. Nació con el objetivo de convertirse en un espacio puente para salvar la distancia que separa a los visitantes del lenguaje del arte contemporáneo, así como dar la posibilidad a los más pequeńos de desarrollar sus capacidades creativas en un lugar no sujeto a las normas que suelen limitar la libertad de acción de los nińos en el desarrollo de actividades plásticas. En ambos casos, lo que defiende este recurso es la importancia de la educación artística, plástica y visual en la formación de los niños y niñas en una sociedad absolutamente dominada e invadida por el lenguaje visual.

\section{Palabras clave:}

educación artística, arte contemporáneo, creatividad, autonomía, ocio cultural, empoderamiento

\section{Abstract:}

MiniTEA Space is a place within the museum Tenerife Art Space, whose raison d'être is to facilitate communication between the public, mainly children and families, and its contents. It was born with the objective of becoming a bridge space to bridge the distance that separates non-specialized visitors from the language of contemporary art, as well as giving the possibility to the youngest to develop their creative capacities in a place not subject to the rules and conventions that usually limit the freedom of action of children in the development of plastic activities. In both cases, what defends this resource is the importance of artistic, plastic and visual education in the education of children in a society absolutely dominated and invaded by the visual language.

\section{Key Words:}

artistic education, contemporary art, creativity, autonomy, cultural leisure, empowerment

\section{Biografía del autor:}

Paloma Tudela Caño (Tenerife, Islas Canarias, 1973). Licenciada en Historia del Arte y en Bellas Artes por la Universidad de La Laguna, y Doctora en Historia del Arte por la misma Universidad, su formación de posgrado se centró en el ámbito de la educación en museos. En 2008 puso en marcha el Departamento de Educación de TEA, que dirige desde entonces y que ha pasado, de ser concebido en su origen como un departamento satélite y dependiente del resto de áreas, a convertirse en un área prioritaria, con una proyección y protagonismo excepcionales dentro de la institución. 
Estos son los hechos:

$1^{\circ}$

El arte contemporáneo es el arte de nuestro tiempo. Nos sintamos más o menos cercanos a él, es el que mejor nos representa, aunque no seamos conscientes de ello; es también el que "habla" sobre asuntos que nos afectan, que nos importan y que, de una $u$ otra manera, determinan nuestra existencia. Es por esto que la extrañeza que mucha gente siente hacia su lenguaje, el desconocimiento, rechazo o desinterés que despierta entre quienes no han tenido la oportunidad de conocerlo, resulta, cuando menos, algo fuera de toda lógica.

$2^{\circ}$

Vivimos absolutamente invadidos por las imágenes, de todo tipo, tamaño, origen y naturaleza. Sin embargo, apenas somos capaces de leer algunas de ellas. Además, en los últimos tiempos, no solo las recibimos, sino que también las producimos y las emitimos de una manera sobredimensionada e igualmente analfabeta. Es decir que, aún sin haber aprendido a leerlas, la inercia del sistema que conforman nos empuja también a producirlas. Los dispositivos móviles han logrado que nos sirvamos de manera compulsiva de un lenguaje cuyos códigos desconocemos y con el que, sin embargo, nos comunicamos (o eso creemos) lanzando mensajes no a un único o a unos pocos interlocutores, sino a millones de ellos ${ }^{1}$.

\section{$3^{\circ}$}

Los niños nacen con una increíble capacidad para aprender, pensar, vivir e interactuar con el mundo de manera creativa, están abiertos a nuevas ideas y tienen un modo innovador de pensar y de resolver problemas. Sin embargo, cuando esos niños llegan a la edad adulta han perdido más del setenta por ciento de estas aptitudes creativas innatas porque, aunque todos nacemos con esta capacidad, si no la estimulamos a través del entrenamiento y la educación, a medida que vamos creciendo va cayendo en un letargo del que difícilmente vuelve a salir.

De una reflexión profunda sobre estos tres

1 Joan Fontcuberta, en su libro La furia de las imágenes, culpabiliza de esta profusión de "imágenes contemporáneas a la deriva” al Homo photographicus: "Por primera vez todos somos productores y consumidores de imágenes, y el cúmulo simultáneo de esta circunstancia ha provocado una avalancha icónica casi infinita” (en J.Fontcuberta: La furia de las imágenes. Notas sobre la postfotografía, Galaxia Gútenberg, Barcelona, 2006, pág. 32) hechos nació en 2015 el Espacio MiniTEA, con la vocación de convertirse en un lugar permanente para la educación dentro del museo, en un espacio "puente" reservado para el encuentro entre el arte contemporáneo y el visitante. Para conseguirlo, lo guían algunos principios básicos, como el uso de una metodología participativa basada en el aprendizaje autónomo y por descubrimiento, el fomento del trabajo colaborativo, el contacto directo con las obras de arte, y el uso de un lenguaje accesible para el conjunto de la población. Todo ello ha convertido a MiniTEA en ese "otro lugar" dentro del museo que el visitante encontrará siempre abierto. Sus ciento ochenta metros cuadrados se dividen en tres ámbitos diferenciados pero conectados, que ayudan a ordenar el uso del espacio y a no "despistarse" del trabajo en cada uno de los tres frentes en los que se trabaja: el de la relación con el arte contemporáneo, el de la descodificación de su lenguaje y el del desarrollo de la creatividad.

\section{Ámbito 1. Miniexpos: otra forma de contar es posible}

El primer ámbito es el que acoge exposiciones de pequeño formato, que cambian cada tres meses y que proponen al público reflexionar sobre temas que surgen del análisis detenido sobre los intereses e inquietudes de los visitantes. El objetivo es conseguir que, al entrar en el espacio, estos visitantes vean las obras, que se detengan unos segundos a observarlas, que se pregunten por ellas, que les maravillen o les desagraden, que capten su atención en un grado suficiente como para permitirles establecer algún tipo de relación con ellas. Es, al fin y al cabo, un lugar donde las obras de arte se presentan al espectador sin los obstáculos que las rodean cuando son expuestas en un espacio de exhibición convencional.

Lo que persiguen todas estas actuaciones es que quien entre al espacio repare necesariamente en las piezas de arte. Buscan obligar al visitante a enfrentarse a las mismas para, inmediatamente después, descubrirle cuáles son las claves que le pueden ayudar a conectar con ellas y sentirse cómodo en su papel de espectador de arte contemporáneo. Esta comodidad es fundamental si se quiere conseguir que la persona haga el espacio verdaderamente suyo y sienta no solo el derecho, sino la curiosidad de volver otro día. Esto ocurrirá si el visitante, además de sentirse cómodo, se da cuenta de que aquello que le presenta la institución tiene que ver con él, que habla sobre el mundo que habita, la sociedad de la que forma parte, y las cuestiones y asuntos que conforman su contexto de vida. He aquí el trabajo invisible y fundamental del Departamento de Educación 


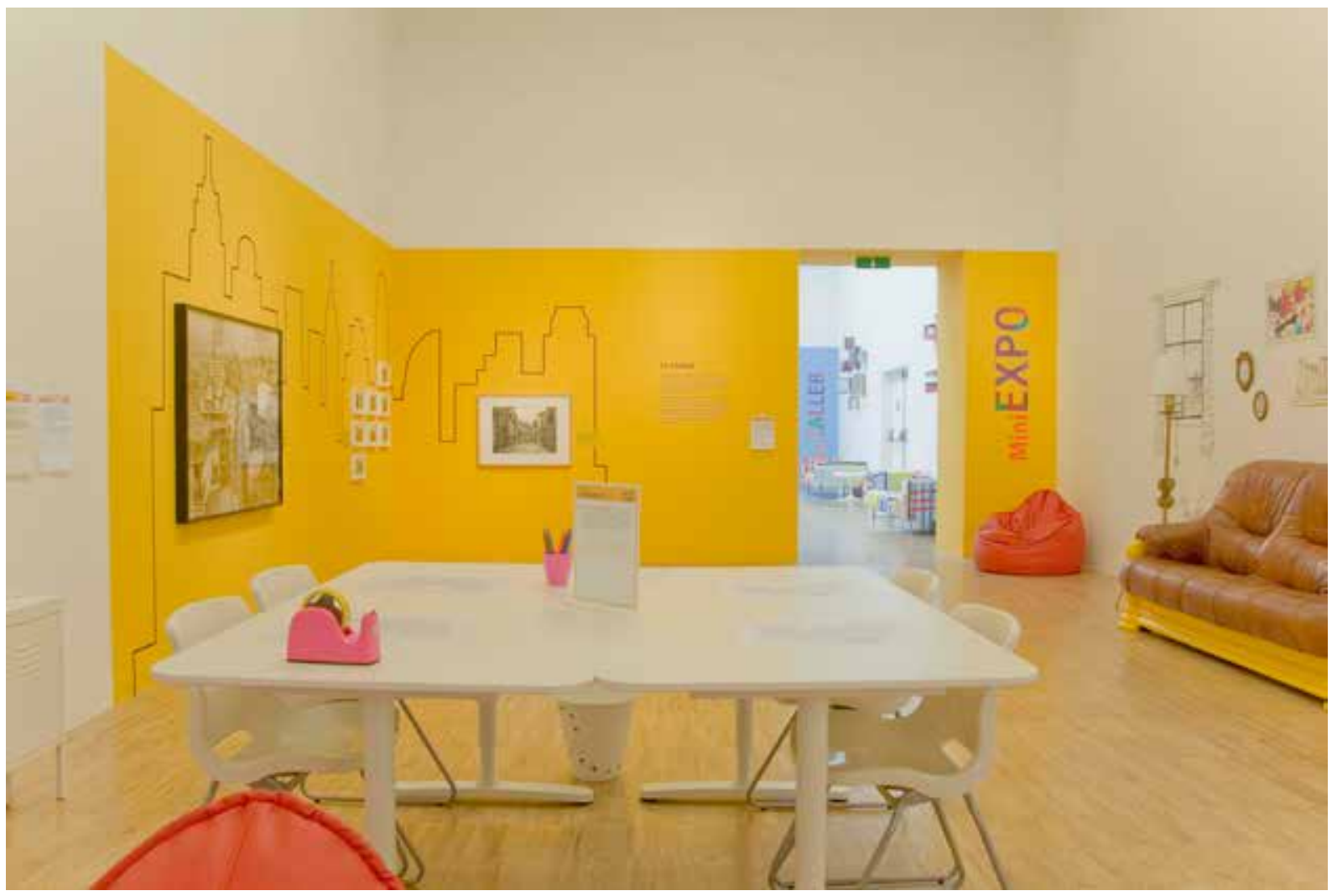

Figura 1. Bravo, J. (2017) Espacio MiniTEA (MiniExpo) [fotografía] Recuperado de https://teatenerife.es/educacion/espacio-minitea/10

porque, si un museo se limita a mostrar obras sin procurar que el público pueda conectar con su lenguaje y descifrar sus códigos, lo único que conseguirá es alejar -aún mása esos visitantes bienintencionados (o, cuando menos, curiosos) que se atreven a adentrarse intramuros.

\section{Ámbito 2. Espacio de descodificación.}

El segundo ámbito del Espacio MiniTEA reúne una serie de propuestas con las que el Departamento. de Educación persigue que niños y mayores se acerquen a los procesos creativos de los artistas cuyas obras se exponen en la miniexpo del ámbito anterior, con el objeto de que puedan aprender a leerlas utilizando las mismas claves que los creadores han empleado para producirlas. Se trata, pues, de hablarle al visitante sobre los procesos creativos del arte contemporáneo, pero de hacerlo en el idioma utilizado por este, esto es, empleando la plástica y las herramientas de producción artística.

Tendemos a explicarlo todo con la palabra, a utilizar el texto para enseñar, aprender, estudiar, memorizar y reflexionar, cuando en realidad la mayor parte de la información que recibimos nos llega hoy a través de las imágenes; cuando es el icónico, y no otro, el universo que nos rodea y que, inevitablemente, además de percibir construimos nosotros mismos. Son muchos los autores que han llamado la atención sobre este hecho. María Acaso habla de que "el mundo como texto ha sido sustituido por el mundo como imagen" (Acaso, 2009) y Kerry Friedman hace lo propio sobre la rapidez con la que "la cultura mundial se desplaza desde la comunicación basada en el texto hacia la saturación de imágenes" (Friedman, 2006). Pero, aunque resulta un hecho evidente y difícilmente refutable sobre el que todos parecemos estar de acuerdo, desde la educación no estamos dándole respuesta.

Afrontar este hecho y alfabetizar a los niños en el uso y aprendizaje del lenguaje visual ya no es una opción; ha pasado al estadio de ser una necesidad. Sino no se considera pronto como tal, comenzaremos a sentir los estragos derivados de una mala o nula comunicación. Además, hay que tener en cuenta que hablamos de una capacidad -la de interpretar la información visual- que no es innata en el ser humano sino que "hay que aprender a desarrollar" (Acaso, 2009), al igual que ocurre con la capacidad de producir esa información. Además de apreciarlas y analizarlas, es importante que aprendamos a construir las imágenes.

El ciudadano del futuro deberá ser un receptor consciente y un productor eficaz de imágenes 


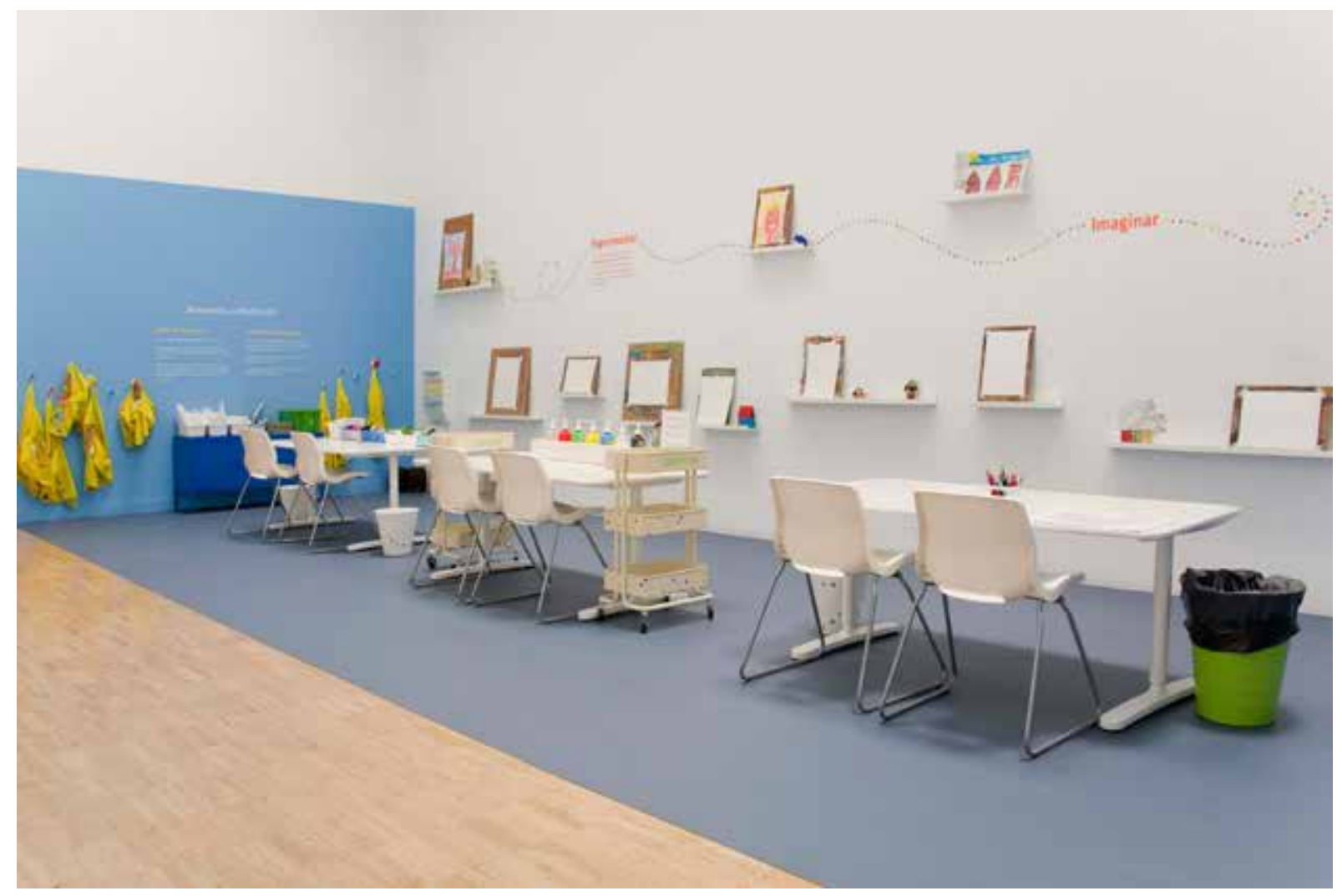

Figura 2. Bravo, J. (2017) Espacio MiniTEA (MiniExpo) [fotografía] Recuperado de https://teatenerife.es/educacion/espacio-minitea/10

y/o obras de arte, de lo contrario, el número de personas analfabetas funcionales en estos ámbitos será cada vez más creciente [...] Las capacidades que se deben desarrollar para alcanzar estas finalidades están relacionadas con: la percepción y lo visual, la manipulación y los procedimientos, y la creación y la expresión (Berrocal, M. Caja, J. Y González, J., 2007, p. 15).

Las propuestas de este segundo ámbito del MiniTEA guían al visitante no solo en el desciframiento de las obras, sino también en la codificación de nuevos mensajes producidos por él mismo, utilizando tanto los códigos y las herramientas propias del lenguaje del arte contemporáneo, como las compartidas por el universo más amplio de la cultura visual, y que incluyen desde el manejo de una barra de grafito hasta el de un programa de edición de vídeos en un dispositivo móvil. De lo que hablamos es entonces del uso del lenguaje del arte contemporáneo para aprender -mucho más allá de lo solamente artístico- a comunicarse en un mundo absolutamente icónico en el que la imagen se ha tornado todopoderosa.

\section{Ámbito 3. Minitaller: la experimentación como herramienta creativa}

Los niños perciben la realidad de una manera muy diferente a como lo hacen los adultos y esta visión personal y única se traduce en el modo que tienen de representar el mundo. Uno de los principales motivos de esta particular mirada infantil es la ausencia de los condicionamientos y de las conductas estandarizadas que la sociedad nos impone conforme vamos creciendo. La forma en que se enfrentan a un papel en blanco difiere radicalmente de la manera en que lo hace un adulto, casi siempre cargado con una mochila repleta de normas, límites, estándares, prejuicios y miedos. $\mathrm{Y}$ es esa diferencia, esa ausencia de contaminación social, la que este tercer ámbito del Espacio MiniTEA se propone utilizar como lugar desde el que contribuir a desarrollar y fomentar la capacidad creativa de las personas.

Para ello el MiniTEA cuenta con un taller de artista que funciona como un atelier compartido para pequeños creadores, en el que los visitantes pueden encontrar mesas, caballetes y estanterías repletas de materiales diversos. Herramientas, pinceles, brochas $y$ demás utensilios se acumulan en este espacio que surgió con la intención de resguardar una buena cantidad de metros cuadrados para que los nińos pudieran contar con un lugar de experimentación plástica, en el que poder 
desarrollar sus capacidades creativas y disfrutar y explotar unas posibilidades de las que normalmente no disponen ni en las aulas de los centros escolares ni en los espacios de sus hogares.

El MiniTaller es un lugar donde se puede pintar en las paredes y donde no importa manchar el suelo ni salirse de la línea de contorno del dibujo. Donde las herramientas y materiales disponibles para trabajar son muchos, diversos y muy diferentes de los normalmente utilizados para llevar a cabo una actividad plástica convencional. Es, al fin y al cabo, un lugar donde probar, experimentar, mezclar, inventar y equivocarse. Donde aprovechar el azar y la casualidad, presentes en cualquier proceso experimental e investigador, y convertir en oportunidad la mancha que deja en el papel la caída de un bote de témpera o la madera astillada de una brocha rota. Un lugar donde cada niño puede trabajar su potencial creativo de manera absolutamente libre, a su ritmo, conforme a sus intereses y dejándose llevar por sus preferencias. Donde se puede colaborar con el otro e intercambiar con él pareceres sobre los procesos propios y ajenos. Un lugar en el que el reloj no determina cuando un trabajo o un proceso han terminado, que ni siquiera establece que tengan que hacerlo.

Además de lo que es el MiniTEA en cada uno de los tres ámbitos que acabamos de describir por separado, en su conjunto todos ellos lo constituyen como:

- Un ejemplo de innovación en el ámbito de la educación, al proporcionar a los niños un lugar para que puedan desarrollar, a través de herramientas de creación plástica, toda su creatividad.

- Una apuesta clara por el desarrollo de la creatividad, una herramienta fundamental para la formación de individuos autónomos, libres y críticos, sea cual fuere el campo del conocimiento en que esa creatividad cultivada en la infancia luego se desarrolle y aplique durante la edad adulta.

- Un lugar inclusivo, en el que niños de diferente nivel social y con diferentes recursos pueden relacionarse y, lo que es más importante, interactuar, compartir y colaborar en la producción de proyectos comunes.
- Una demostración de la importancia que una institución museística pública otorga a su función educativa, proporcionando los medios humanos, materiales y estructurales necesarios para que pueda desarrollarse de manera óptima.

Comenzamos investigando sobre la ciudad y ahora mismo lo estamos haciendo sobre la representación de la mujer en la historia del arte occidental. En ambos casos, como en todos los temas que hemos desarrollado entre aquel primero y este último, el enfoque es el de un equipo de educación que privilegia sobre todas las cosas la comunicación con el visitante, que prioriza el derecho de todas las personas que entran en el museo a poder relacionarse con las obras de arte, que confía plenamente en las capacidades creativas de los más pequeños y que apuesta firmemente por su desarrollo como clave para una educación mejor y más completa. Una educación que les haga personas más felices y autónomas y con más herramientas a su disposición, no sólo para crear y comunicarse plásticamente, sino para interpretar, discriminar y desarrollar un sentido crítico que se ha revelado absolutamente fundamental en un mundo invadido por cientos de miles de millones de imágenes que no deberíamos seguir engullendo sin más.

\section{Referencias}

Acaso, M. (2009). La educación artística no son manualidades. España: Catarata.

Fontcuberta, J. (2006). La furia de las imágenes. Notas sobre la postfotografia. Barcelona: Galaxia Gútenberg.

Friedman, K. (2006). Enseñar la cultura visual. Espańa: Octaedro.

Berrocal, M. Caja, J. Y González, J. (2007). La educación visual y plástica hoy. Educar la mirada, la mano y el pensamiento. Barcelona: Grao. 